\title{
Developing Software Quality and Testing Capabilities in Hispanic America: Challenges and Prospects
}

\author{
Ignacio Trejos-Zelaya
}

\begin{abstract}
This chapter presents a summary of the Hispanic America region status and prospects in software engineering-particularly those regarding software quality and software testing.
\end{abstract}

Keywords Software testing - Software quality - Software tester · Software testing skills $\cdot$ Software engineering

\section{Introduction}

By the turn of the century, humankind had already entered the information age. Modern societies have grown increasingly dependent on information and technology for their proper functioning, growth and survival. For over two decades, developed countries have found that shortages of capable Information Technology (IT) workers may hinder their prosperity [1].

In the last years of the twentieth century, the IT sector was experiencing an abrupt growth [2, 3]. The Computer World weekly reported an exceptional growth of IT employment positions: from 160,000 jobs in 1997 to 800,000 in year 2000 [4].

In emerging economies such as those in Spanish-speaking America, software development has opened opportunities for establishing export and outsourcing services industries. For example, during the same period, Costa Rica had software companies and start-ups exporting successfully to Latin America and North America, growing at a rate of $40-60 \%$ in headcount $[5,6]$.

A successful software ecosystem requires that all aspects of software development, integration, reuse, and maintenance be considered and performed with excellence. Most computing higher-education programmes in Latin America lean either towards Computer Science or Information Systems [7]; although most include several programming courses in their curricula, few of them embrace Software

\footnotetext{
I. Trejos-Zelaya

Universidad Cenfotec \& Tecnológico de Costa Rica, San José, Costa Rica
} 
Engineering as their main subject, and still less do focus on software quality and/or software testing.

We shall present a view on the challenges ahead for the development of software quality and testing capabilities in Spanish-speaking America and prospects for its expansion and progress.

After this Introduction, the chapter is organised as follows: the next section provides a background on the evolution of computing in Latin America since the 1950s to the present day, then goes into describing workforce demand and supply and skill sets required for IT and particularly in software engineering, emphasizing those related to individual and social competencies. Examples of the Hispanic America software industry are provided, followed by a discussion of the impact of professional certification schemes on software quality and testing on the region. Then, the situation of Hispanic America post-secondary education on software engineering is presented, with specific analysis of the author's environment-Costa Rica. The chapter concludes with a view on the challenges ahead and promising prospects lying in the future of software quality and software testing in Hispanic America.

\section{Background}

Computing in Latin America started in the late 1950s when the first computers were introduced in countries such as Mexico, Brazil, Colombia and Chile [8]. Da Costa [9] asserts that, since those times, computing in Latin America has been influenced mostly by the USA and, to a lesser extent, Western Europe. Economic, political and social matters were diverse during the 1960s and 1970s, and had an influence on the development of computing-related higher-education programmes and local IT ecosystems; there are significant variations in the evolution of IT among countries. Larger countries, such as Mexico, Brazil and Argentina, started assimilating computing technologies earlier than smaller ones. First users were universities, governments and large corporations (some state-owned).

First degree programmes appeared close to engineering, mathematics or science faculties. Among the first were Argentina's Universidad de Buenos Aires, which established in 1962 a scientific computing programme as a sequel to their Instituto de Cálculo (Calculation Institute). National Polytechnic Institute founded their degree programme in computing engineering in 1965, followed by the National Autonomous University of Mexico (UNAM). Venezuela, Chile, Colombia and Peru followed suit in the late 1960s. About the same time, in Costa Rica, industrial IT players (IBM and Burroughs) offered training courses in programming and system administration to engineering and science students and professionals to grow local capabilities for operating and developing computing systems. During the 1970s, most Latin American countries established educational programmes related to computing. Terminology was diverse; frequently appearing terms were 'Informática' (Informatics), 'Computación' (Computing) or 'Ingeniería de Sistemas' (Systems Engineering). Colombia’s Universidad Nacional established the 
first master's program in Computer Science in Latin America. Brazil was first in creating doctoral programmes and, together with Chile, has grown scientific capabilities more widely than all other Latin American countries.

Latin America has experienced the same IT transitions that have occurred in more developed countries, typically with a lag of 1 to 5 years as compared to the originating technology's country. Overall, Latin America has been mostly a follower in computing hardware innovation. Brazil set trade barriers to protect its industry, then funded doctoral scholarships for studies abroad with a view to build its scientific and technological research and development capabilities. Upon returning, scholars help build national research laboratories or centres at universities. Brazil currently incorporates digital technologies to create an innovative environment to foster economic development.

Chile stimulates Digital Government and nurtures public-private collaboration for innovation in education and business. Smaller countries, such as Costa Rica and Uruguay, obtained loans from the Inter-American Development Bank aimed at supporting their software industries' export capabilities through improving quality and productivity in companies, updating university curricula, building institutional competencies and promoting innovation and entrepreneurship. Colombia and Mexico sponsor technology parks and regional initiatives for industrial clusters that include digital technologies and services companies.

Nowadays, due to the proliferation of the Internet (and the World Wide Web) and mobile communications, digital technologies have become pervasive in Latin America. Broadband access, together with smart phones, laptops and digital TV sets, has opened a market of enormous proportions, in a very short time frame: "442 million unique mobile subscribers across Latin America and the Caribbean, accounting for $68 \%$ of the [sub-continent] population" [10]. Digital Transformation is on the rise in the Americas, demanding more and more software applications to enable and sustain transformed business processes or new endeavours.

\section{Skill Sets}

In the report 'The Future of Jobs', The World Economic Forum [11] states:

Disruptive changes to business models will have a profound impact on the employment landscape over the coming years. Many of the major drivers of transformation currently affecting global industries are expected to have a significant impact on jobs, ranging from significant job creation to job displacement, and from heightened labour productivity to widening skills gaps. In many industries and countries, the most in-demand occupations or specialties did not exist 10 or even five years ago, and the pace of change is set to accelerate.

Digital technologies have been instrumental to changes impacting nearly every human activity worldwide. Those technologies, themselves, have made great strides in the last 60 years, influencing and accelerating scientific, technological and business development overall. 
The 'IT skills' gap refers to the shortage of qualified candidates to fulfil open positions in occupations related to digital technologies. The problem has been reported several times $[12,13,14]$, and it appears in many ways $[8,15]$ :

- A deficit of educated candidates to fulfil job openings

- Candidates who are inadequately prepared for certain IT positions

- New occupations generated by technological change and innovation

- Novel business models, products, and services

- Need to retrain personnel for assimilating acquired technologies

- Requirement to operate and maintain information systems built on technologies no longer taught at universities

- Impaired diversity due to underrepresentation of women and ethnic minorities in the IT workforce, which negatively impacts innovation, productivity, creativity and prosperity

- Institutions slow in designing and updating curricula to educate future technologists and developing programmes to retrain those already employed

Most Latin American countries report that demand of IT skills exceeds supply. However, there is more to those situations:

- Diversity of skills required in the labour market is scarce or even unknown (e.g. storage, digital forensics, data science, cloud computing, blockchain, artificial intelligence, Internet of Things).

- Quality of the education of IT graduates is uneven: range of knowledge, depth of know-how, significance of experience, certification of skills, mastery of domain, in addition to an understanding of their discipline's foundations.

\subsection{Software Engineering}

As a computing sub-discipline, Software Engineering's origins can be traced back to the 1960s, particularly the first Software Engineering Conference sponsored by the NATO in October 1968 [16]. Here we quote some relevant parts of the report:

The discussions cover all aspects of software including

- Relation of software to the hardware of computers

- Design of software

- Production, or implementation of software

- Distribution of software

- Service on software

Some other discussions focussed on subjects like:

- The problems of achieving sufficient reliability in the data systems which are becoming increasingly integrated into the central activities of modern society

- The difficulties of meeting schedules and specifications on large software projects

- The education of software (or data systems) engineers

- The highly controversial question of whether software should be priced separately from hardware 
In 1975, the IEEE Computer Society started publishing the IEEE Transactions on Software Engineering as a bimonthly peer-reviewed scientific journal and also sponsored the first edition of what became the International Conference on Software Engineering; both continue to this day. It was followed by the IEEE Software magazine in 1984. The British Computer Society sponsored publication of the Software Engineering Journal (1986-1996, now available via IEEE Xplore), and several more conferences and refereed journals related to facets of Software Engineering have appeared since the 1980s.

By year 2000, Finkelstein and Kramer defined Software Engineering as "the branch of systems engineering concerned with the development of large and complex software intensive systems. It focuses on: the real-world goals for, services provided by, and constraints on such systems; the precise specification of system structure and behaviour, and the implementation of these specifications; the activities required in order to develop an assurance that the specifications and realworld goals have been met; the evolution of such systems over time and across system families. It is also concerned with the processes, methods and tools for the development of software intensive systems in an economic and timely manner" [17].

Recognising the need to establish software engineering as a profession, the Association for Computing Machinery (ACM) and the IEEE, established the Software Engineering Coordinating Committee in 1993 to jointly work on:

- Defining a Body of Knowledge on software engineering (SWEBOK, now in its third version [18])

- Agreeing on a Software Engineering Code of Ethics and Professional Practice [19]

- Developing curriculum recommendations on software engineering for undergraduate [20] and graduate education [21]

- Describing a set of competencies, at five levels of competency [22] (SWECOM)

SWEBOK's objectives are:

1. To promote a consistent view of software engineering worldwide

2. To specify the scope of, and clarify the place of software engineering with respect to other disciplines such as computer science, project management, computer engineering, and mathematics

3. To characterize the contents of the software engineering discipline

4. To provide a topical access to the Software Engineering Body of Knowledge

5. To provide a foundation for curriculum development and for individual certification and licensing material

Some organisations have sponsored the development of professional certifications on software quality and software testing:

- American Society Software Quality Engineering (ASQ): Certified Software Quality Engineer [23] since 1996

- International Software Testing Qualifications Board (ISTQB): Founded in 2002 by 8 country members (Austria, Denmark, Finland, Germany, the Netherlands, 
Sweden, Switzerland, and the UK), it now includes 59 member boards. Based on pioneering work by the British Computer Society's Information Systems Examinations Board (ISEB) and the German Testing Board, ISTQB has been developing a comprehensive set of qualifications assessments related to software testing — both technical and managerial—in various levels [24]:

- Foundation level

- Foundation level extension (agile, model-based tester, automotive software, mobile application, acceptance, performance, usability)

- Advanced level (test manager, test analyst, technical test analyst, agile technical tester, security tester, test automation engineer)

- Expert level (improving the testing process, test management)

- Institute of Electrical and Electronics Engineers (IEEE), Computer Society (IEEE/CS): associate software developer, professional software developer, and professional software engineering master. IEEE/CS offer review courses based on the SWEBOK that help candidates prepare for certification assessments. Two such courses cover software quality and software testing.

- International Software Quality Institute (iSQI): develops its own professional certifications and exams supporting other organisations' certification programmes. Areas covered include: software testing, management, software architecture, requirements engineering, software development, usability, and agile methods.

Standards for software development started to appear in the 1960s. The IEEE has been developing the most comprehensive family of civilian Software Engineering Standards since the 1980s. Also relevant are standards promoted by the ISO and the IEC. Some of those standards are particularly relevant to software quality and software testing:

- Software Quality Assurance Processes (IEEE Std 7304)

- System, Software, and Hardware Verification and Validation (IEEE Std 1012)

- Software Reviews and Audits (IEEE Std 1028)

- Software Testing (ISO/IEC/IEEE 29119)

- Configuration Management in Systems and Software Engineering (IEEE Std 828)

- Classification for Software Anomalies (IEEE Std 1044)

- System and software quality models (ISO/IEC 25010, preceded by ISO/IEC 9126)

- Software Requirements Specifications (IEEE Std 830)

- Software Life Cycle Processes (ISO/IEC/IEEE Std 12207)

- System Life Cycle Processes (ISO/IEC/IEEE Std 15288) 


\subsection{Human Competencies}

At the turn of the present century, industry and professional associations, as well as academic forums recognised the need to better prepare future professionals for life in the workplace. Some engineering educators called for a more rounded and integrative approach, as opposed to the prevailing analytical and reductionist model [25]. The USA's National Academy of Engineering stated these needed attributes of engineers by year 2020 [26]: strong analytical skills; practical ingenuity; creativity; communication; business and management; leadership; high ethical standards; professionalism; dynamism, agility, resilience, and flexibility; lifelong learning.

Those attributes agree with the findings reported in what employers express in surveys presented in [7] and [27], where the human, non-technical, attributes mentioned by $50 \%$ or more of the respondents include: leadership; ability to work in a team; communication skills (written and verbal); problem-solving skills; work ethic; initiative; analytical/critical/quantitative skills; flexibility/adaptability; interpersonal skills; organizational ability; strategic planning skills.

There is a trend in engineering education and accreditation schemes to include 'soft skills' in addition to more 'engineering skills' as part of graduate attributes from engineering degrees. The foremost example is the International Engineering Alliance (IEA) Graduate Attribute Profile [28], "Graduate attributes form a set of individually assessable outcomes that are the components indicative of the graduate's potential to acquire competence to practise at the appropriate level"; these comprise: (1) engineering knowledge, (2) problem analysis, (3) design/development of solutions, (4) investigation, (5) modern tool usage, (6) the engineer and society, (7) environment and sustainability, (8) ethics, (9) individual and team work, (10) communication, (11) project management and finance, (12) lifelong learning.

Professional work in software quality assurance or software testing improves when individuals have developed their communication and teamwork capabilities. For example, we highlight the matter with quotations taken from [29]:

- Errors may occur for many reasons, such as [... ] Miscommunication between project participants, including miscommunication about requirements and design

- A tester's mindset should include curiosity, professional pessimism, a critical eye, attention to detail, and a motivation for good and positive communications and relationships

- In some cases organizational and cultural issues may inhibit communication between team members, which can impede iterative development

- Additional benefits of static testing may include: [...] Improving communication between team members in the course of participating in reviews

- Potential drawbacks of test independence include:

- Isolation from the development team, leading to a lack of collaboration, delays in providing feedback to the development team, or an adversarial relationship with the development team

- Developers may lose a sense of responsibility for quality

- Independent testers may be seen as a bottleneck or blamed for delays in release [...] 
With regard to personal competencies, two project management professional associations, the International Project Management Association (IPMA) and the Project Management Institute (PMI), have developed competency models that include 'behavioural', 'people' or 'personal' competencies: IPMA Individual Competence Baseline and PMI Project Manager Competency Development Framework, respectively. Key traits identified: leadership (leading), relations \& engagement, teamwork, managing, motivation, assertiveness, self-reflection \& self-management, personal communication (communicating), relaxation, openness, creativity, cognitive ability, resourcefulness, results orientation, efficiency, effectiveness, consultation, negotiation, conflict \& crisis, values appreciation, personal integrity \& reliability, ethics, professionalism.

\section{Industry}

For nearly 30 years, Computer Science programmes have sported 1 to 4 courses (typically 2) related to software development, sometimes including one or two 'capstone' project(s). A major problem faced by the industry worldwide is that university-level degree programmes on software engineering, as something distinct from Computer Science or Information Systems, have appeared only recently (Rochester Institute of Technology's was the first such in the USA, in 1996).

Industry has had to cope with the situation and invest in training their personnel beyond the programming skill-set that recent graduates bring when recruited. Fresh graduates lack the subject knowledge and the discipline required for professional software engineering, but can learn quickly.

Latin America has not been a major worldwide player in the product-oriented software industry. Each country has developed its own software industry, serving local needs, and some companies have been successful in growing software services for export. Aiming at strengthening their export capabilities, smaller countries, such as Costa Rica and Uruguay, reached the Inter-American Development for funding improvements of their software companies' productivity and quality, upgrading and updating university curricula, building institutional competencies, fostering innovation and entrepreneurial initiatives, in addition to expanding industry-academia collaboration.

Software services comprise development, maintenance, migration, support and testing. Mexico's Softtek (www.softtek.com) is the largest Latin American IT company. Softtek offers diverse technology and business transformation services, and is credited to inventing the nearshore concept - serving mainly North America in compatible time zones. Softtek adheres to the Capability Maturity Model (CMMi) and has achieved its level five. It also uses Six Sigma as a customer-focused and data-driven management method for problem resolution, business process excellence and process improvement. Within an extensive service portfolio, Softtek offers QA and software testing services using their own software QA \& validation methodology and quality assurance and validation maturity model. In QA and 
testing, their services comprise: quality assurance, software testing, test automation, performance testing, mobile software testing, security and penetration testing and agile software testing. The company is led by Blanca Treviño since year 2000 and has subsequently experienced steady growth. Ms. Treviño has also been a role model for women in technology, helping initiatives to attract female talent to IT. In order to overcome limitations of new hires in software testing and quality assurance, Softtek has a wide-ranging training and career development programme, which also includes bridges to industry-recognised professional and technical certifications.

Notable amongst Latin American companies is Choucair Testing http://www.cho ucairtesting.com Founded in 1999 by María Clara Choucair, the company focusses on software testing and quality assurance services. Their approach, known as Business Centric Testing (BCT), concentrates on designing an appropriate service adapted to each client company's business model, competitive strategy and user experience. Choucair Testing has become the largest Hispanic America provider of software quality assurance and testing services. Building upon its experience in the banking and finance industry, Choucair now covers more application and business domains with diverse technologies. Their testing services comprise: functional testing, performance testing, mobile testing, web testing, business intelligence testing, usability testing, accounting \& finance testing, migration testing, comprehensive system testing, comprehensive acceptance testing, automation testing, SAP automation testing, payroll testing, security testing, transactional switch testing, internationalisation and localisation testing, testing environment preparation and continual improvement, technology and knowledge transfer.

As the need for controlling, testing and improving software quality grows in Hispanic America, the region has witnessed the appearance of more companies specialising in those services. Countries such as Mexico, Costa Rica and Uruguay have been successful in attracting foreign direct investment from technology companies who either establish their own units or centres of excellence on software testing, or seek to outsource or out-task to specialist companies. Thus, the demand for professionals knowledgeable on software quality and testing has grown steadily during the last decade.

\section{Impact of Professional Certification Schemes}

Motivated by the need to grow and improve her company's chosen domain of expertise, María Clara Choucair sought out training frameworks and certification schemes in order to develop Choucair Testing's specialist workforce. She found the ISTQB certification schemes and, with help from the Spanish Software Testing Qualifications Board (SSTQB) and the International Software Quality Institute (iSQI), led the establishment of the Hispanic America Software Testing Qualifications Board, as a regional member of the ISTQB. 
In Costa Rica, companies such as Electronic Data Systems (EDS) and HewlettPackard prompted their engineers to seek certifications by the BCS's Information Systems Examination Board (ISEB), prior to becoming a member country of the HASTQB Regional Board within the ISTQB. Before that, from 2003 to 2010, courses for preparing for ASQ's Certified Software Quality Engineer were run by Cenfotec (www.ucenfotec.ac.cr); some 120 professionals hold the CSQE in Costa Rica, most of them working in the biomedical device sector. ASQ's impact has been wider and long-standing in the Manufacturing and Life Sciences sectors in Costa Rica (certifications on Quality Auditor, Quality Engineer, Six Sigma Black Belt, Six Sigma Green Belt, Six Sigma Yellow Belt).

ISTQB professional certifications in software testing have been growing steadily in Hispanic America in recent years. At the close of 2018, 7499 professionals had earned one or more ISTQB certifications. This can be observed in Fig. 1.

Hispanic America follows the worldwide trend of Foundation being the most sought after certification level, as can be seen in Fig. 2.

Figure 3 shows the distribution of certified professionals per country in the Hispanic America region.

It is clear that Colombia leads the pack in Hispanic America. Costa Rica's progress since 2013 has been steady, due to the growth in demand for certifications and market recognition of software testing and software quality assurance as professional fields of endeavour. This can be seen in Fig. 4.

Costa Rica's growth can be traced to a very productive collaboration between academia and industry. Starting around 1999, some universities have offered scant and scattered training on software quality assurance and software testing, but more frequently since year 2014 — with Universidad Cenfotec taking the lead since 2004.

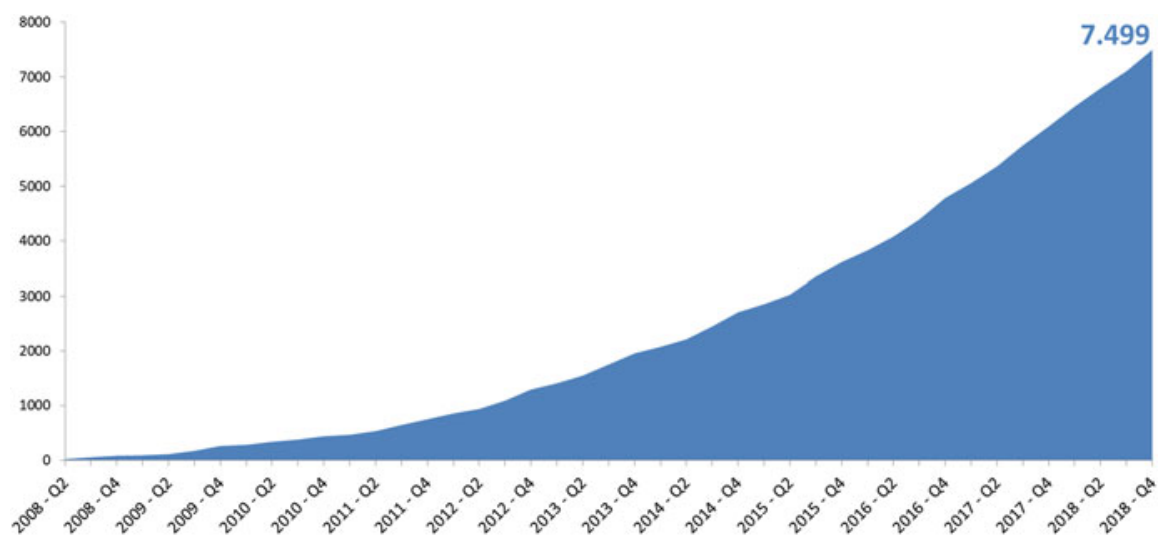

Fig. 1 Evolution of ISTQB Software Testing certifications in Hispanic America 2008-2018 


\section{HASTQB - Distribution of certifications}

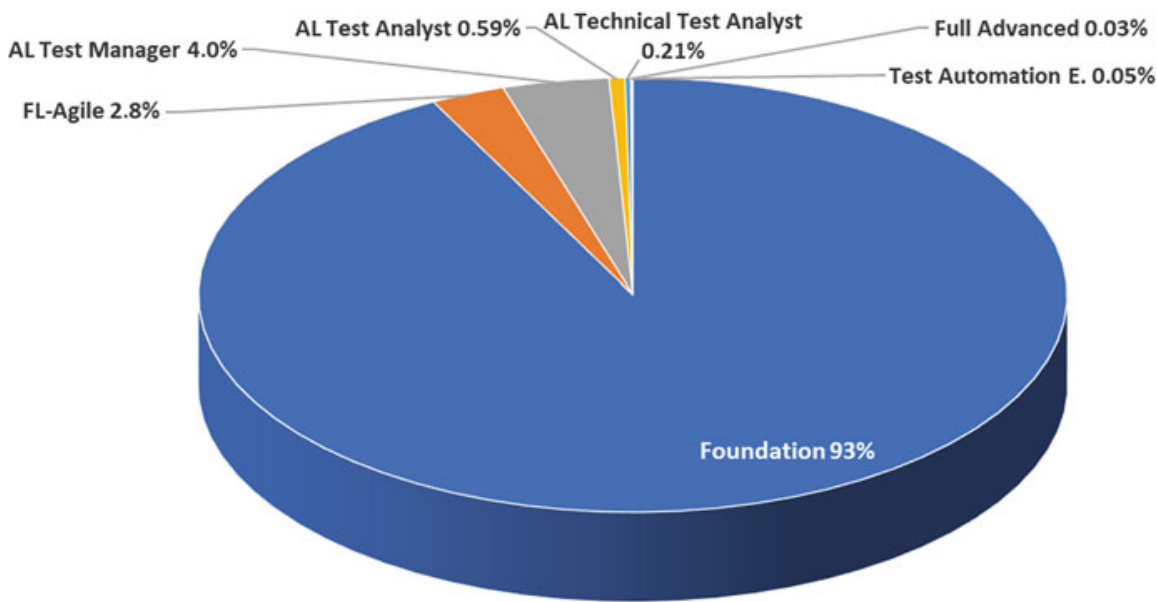

Fig. 2 Hispanic America distribution of software testing certifications, per ISTQB levels

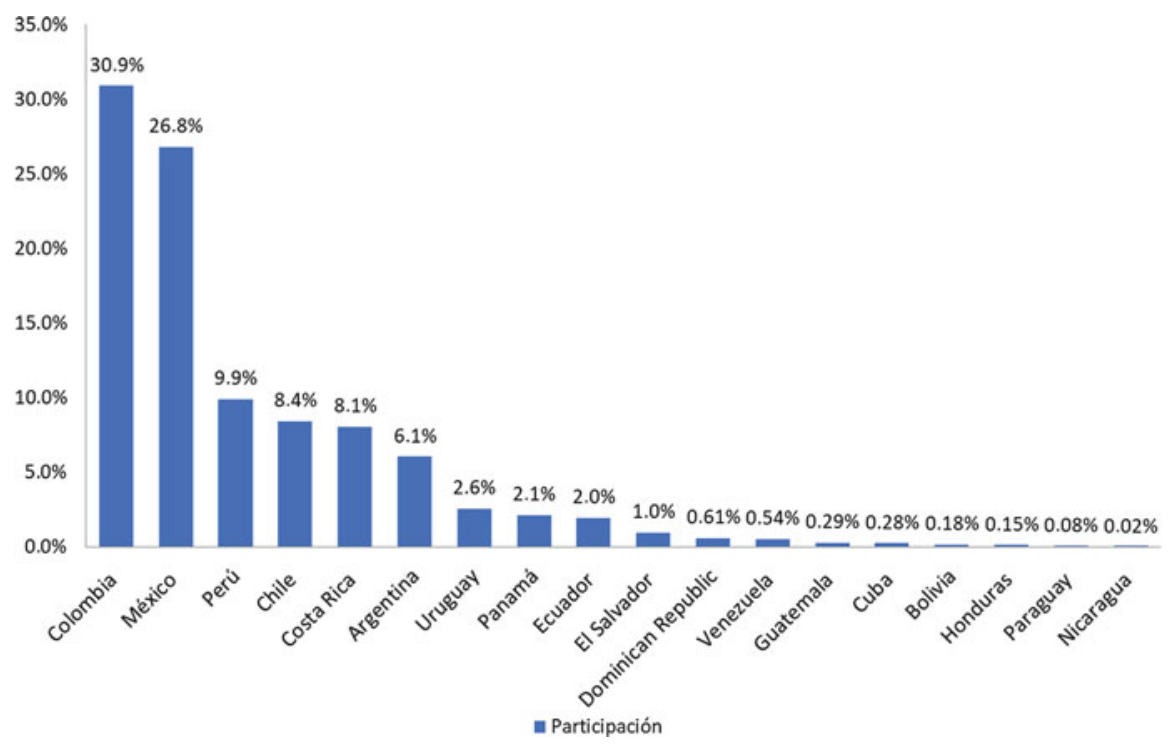

Fig. 3 Distribution of ISTQB's certification per Hispanic American country 
$\mathrm{N}^{\circ}$ Certified Testing Professionals (Costa Rica)

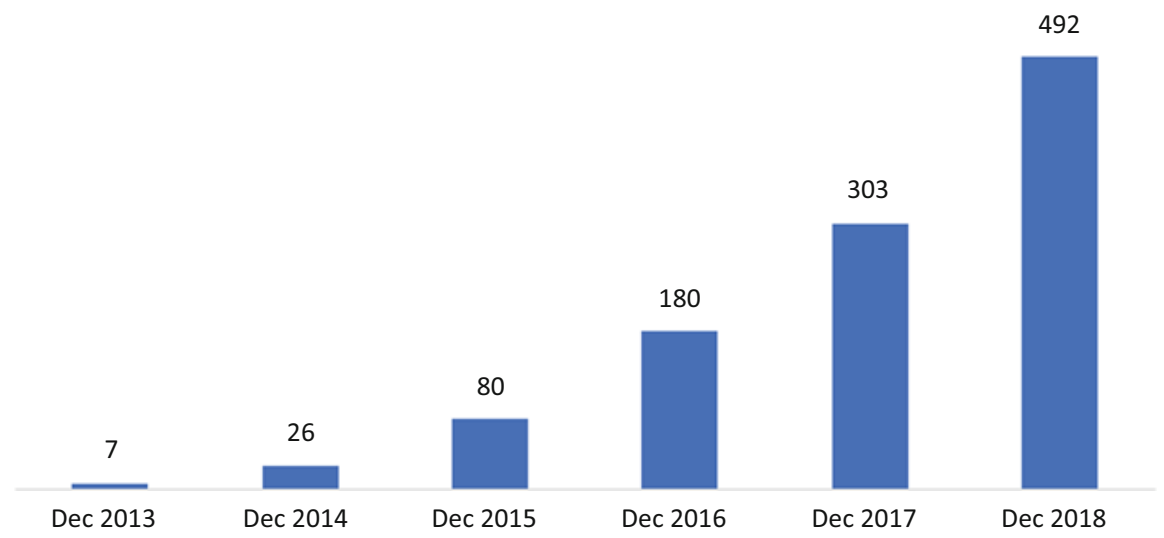

Fig. 4 Growth of certified testing professionals in Costa Rica, 2013-2018

\section{Higher Education on Software Quality and Testing}

In Hispanic America there are very few degree programmes on Software Engineering, as such. Costa Rica and Panama were among the first countries to develop full degree programmes focussing on Software Engineering. Other countries have 'Systems Engineering' programmes that blend computer science, information systems and software engineering knowledge areas. The result is that few degree programmes on computing provide sufficient space for software quality assurance processes, software verification and validation, software or software testing.

It not just a matter of knowledge, for experience is lacking as well as attitude. This explains the difficulties faced by employers in hiring recent graduates with basic competencies on software quality and testing. Large companies such as Softtek and Choucair Testing have developed training programmes that start with foundational courses and workshops functional software testing, and then progress towards testing analysis, technical testing, security testing, performance testing, usability testing, Web testing, mobile testing, testing management, agile testing practices, testing process improvement and software quality assuranceamong others. Smaller companies have a reduced assortment of training courses or workshops, and resort to guided self-study or mentored study groups. Syllabi from the ISTQB and ASQ (CSQE) certifications have provided guidance for organising and aligning course content or studies.

The above poses challenges for designing innovative curricula at universities and colleges. The following section offers examples from university experiences in Costa Rica. 


\subsection{Curriculum Design and Development Experiences in Costa Rica}

Professors from the Costa Rica Institute of Technology (TEC, Tecnológico de Costa Rica) and the University of Costa Rica (UCR, Universidad de Costa Rica) developed extension training courses (continuing education) and consultancies on software quality assurance, software processes and methodology and software testing around 1995. Course contents and consultancies were mostly based on IEEE's Software Engineering standards. By 1997, Prof. Marcelo Jenkins developed software metrics and software processes courses MSc in computing. Open and in-house training courses on software quality assurance were offered by TEC in 1999 and 2000.

\subsubsection{Cenfotec}

In year 2000, Cenfotec was founded as a technical college by a group of software development entrepreneurs and academics interested in contributing to Costa Rica's knowledge-based economic development. Cenfotec started offering a 2year programme on software development, grounded on Software Engineering. The first three terms of the original programme included a software engineering project, three technical courses and one English for IT course (nine computing science and software engineering courses, three English courses, three software engineering projects). A fourth term comprised a practicum (internship) and two technical elective courses. The three integrative software engineering projects were the curriculum backbone; each exercised requirements elicitation, analysis and specification, software design, construction and testing, with different technological mixes and processes. The projects were incremental, progressively integrating knowledge and skills required for problem-solving using systematic engineering processes, employing an approach that helped grow intertwined 'hard' and 'soft' skills required for teamwork and future professional endeavours. Experience-driven learn-by-doing collaboratively computing products or services was implemented within projects by teams of students that performed roles inspired by Watts Humphrey's Team Software Process [30] and the Rational Unified Process [31]. Actual teamwork was achieved: 4 to 6 team members collaborate, performing roles for which they are accountable, employing emotional and social intelligences as cornerstones [32], and developing good work habits [33]. Benchmarking against the SWEBOK v0.95, revealed the need to improve software testing education.

In July 2003, Cenfotec agreed with Universidad Latina (Costa Rica's largest private university) to develop there Costa Rica's first Software Engineering degree programme, as a continuation of Cenfotec's 2-year programme. The knowledge content was validated against a draft of the Software Engineering Education Knowledge (SEEK), that was published by a year later by the Association for Computing Machinery and the Institute of Electric and Electronic Engineers's Computer Society [34]. That Software Engineering degree had improved coverage 
of software process, software quality assurance, software testing and software configuration management, in addition to reinforced strengths in requirements, design, construction and the project approach. Figure 5 shows a view of the knowledge mapping performed against the SEEK.

As stated above, most computing degrees typically lack software testing and quality assurance content. This prompted curriculum design work towards specialisations on software quality and testing. Between years 2002 and 2005, Cenfotec developed continuing education courses on software quality assurance and software testing, and also offered preparation towards ASQ's Software Quality Engineer certification (years 2003-2010). With the help of Costa Rica's Investment Promotion Agency (CINDE, www.cinde.org/en) and collaboration from 13 companies ${ }^{1}$, Cenfotec designed and validated a Software Testing and Quality Technician programme in 2009, targeted at people with some education in programming; the programme failed to attract sufficient students. Curricula for postgraduate programmes on software quality engineering and testing were drafted between 2004 and 2008. From 2009 to 2011, Cenfotec pursued authorisation to obtain formal university status.

In order to improve continuing education and design postgraduate specialisations, Cenfotec contacted the Hispanic America Software Testing Qualifications Board (HASTQB) in 2009, and Costa Rica gained membership in 2010. For curriculum design, knowledge input was sought at ISTQB's syllabi (Foundation and Advanced levels) and CSQE's Body of Knowledge. Another valuable source was $\mathrm{O}_{*}$ NET [35], a database with standardized descriptors on about 1000 occupations in the USA, provided knowledge, skills, tasks and work characterisations related to software testing and quality engineering. Curricula for software quality engineering and software testing were designed and validated during 2010 and 2011, including coverage analysis of syllabi from ISTQB's advanced-level certification schemes (test analyst, technical test analyst, test manager). A six-course specialisation was launched in late 2011. Figure 6 illustrates some of the task abilities identified and validated for graduates of the specialisation ('E') or a future Master's ('M') programme.

Cenfotec was granted university status in December 2011, and started operating as Universidad Cenfotec in January 2012. By now, it has several postgraduate studies programmes, which include an MSc in database technology (comprising data analytics and data management) and an MSc in cybersecurity. Although a full-fledged MSc in Software Testing \& Quality Engineering was designed, market research revealed that it was not advisable to launch it yet. A forthcoming MSc in Software Engineering will have software quality engineering and advanced software testing among its concentrations. The current degree programme in software engineering includes four software engineering projects where students apply the basics of software processes, software configuration management, software testing and

\footnotetext{
${ }^{1}$ AdvanceMe, Avántica Technologies, Babel Software, Experian, Hewlett-Packard, Intertech International, L.L.Bean, Qualitas Factory, RoundBox Global, Schematic (now Possible Worldwide), TestingSoft, Via IT, Wal-Mart.
} 


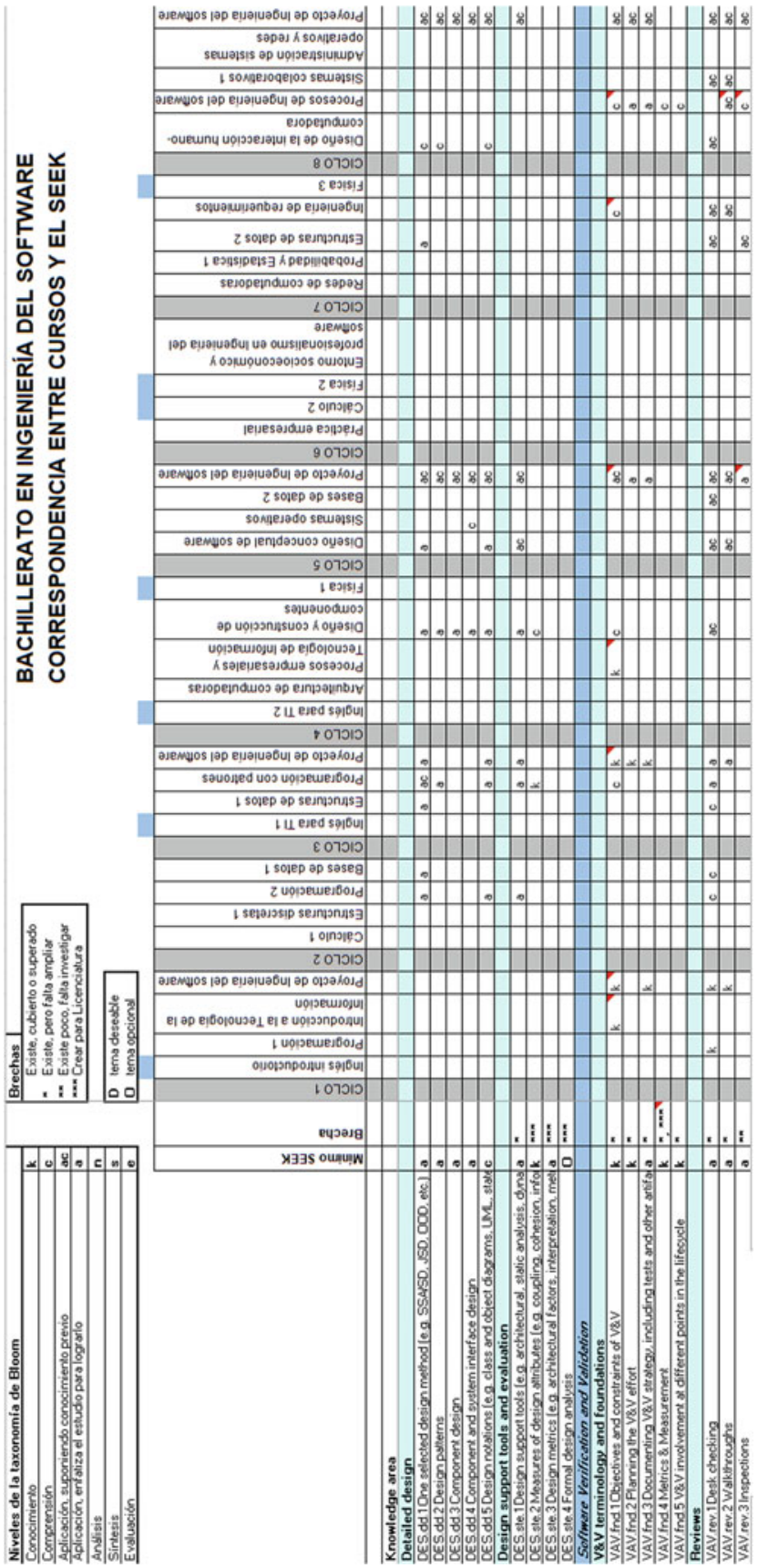




\begin{tabular}{|c|l||}
\hline E & Design test plans, scenarios, scripts, or procedures. \\
\hline E & Test system modifications to prepare for implementation. \\
\hline E & Develop testing programs that address areas such as database \\
\hline E & Document software defects, using a bug tracking system, and report \\
\hline E & Identify, analyze, and document problems with program function, \\
\hline E & Monitor bug resolution efforts and track successes. \\
\hline E & Create or maintain databases of known test defects. \\
\hline M & Plan test schedules or strategies in accordance with project scope or \\
\hline E & Participate in product design reviews to provide input on functional \\
\hline E & Review software documentation to ensure technical accuracy, \\
\hline E & Document test procedures to ensure replicability and compliance \\
\hline E & Develop or specify standards, methods, or procedures to determine \\
\hline E & Update automated test scripts to ensure currency. \\
\hline
\end{tabular}

Fig. 6 Fragment of software quality engineer graduate profile (task abilities). Cenfotec (2009)

quality assurance; in addition to the projects and several courses on programming, requirements, design and construction, there are courses going deeper on software engineering processes and software verification and validation.

As of this writing, Cenfotec is launching two new programmes on software testing: Software Testing Technician (four terms, nine courses), Software Test Analyst postgraduate programme (five courses, five certifications aligned with ISTQB, IREB and Selenium).

\subsubsection{State Universities}

Since 2008, the Distance Education University (UNED) offers a Postgraduate Diploma ('Licenciatura') on Informatics Engineering and Software Quality ('Ingeniería Informática y Calidad del Software') which includes nine courses and a final project (either an internship or a directed research). The courses include: IT systems quality management, advanced requirements engineering, quality systems, change management, configuration management, IT marketing, analytical methods and software quality metrics, software quality control and software quality certification models.

The Costa Rica Technical University started offering a degree programme on software engineering in 2011, which includes one course on software quality and another on software quality management and validation. The Costa Rica Institute of Technology started in 2012 a new version of its reputed Computing Engineering degree ('Ingeniería en Computación'), which included, for the first time since 1976, a course covering the foundations of software testing, software quality assurance and software configuration management; input from employers and graduates were the main reason for including such a course in the curriculum. In 2017, the University of Costa Rica made a major change in its prestigious Computer Science 
and Informatics 4-year degree programme. After completing 2 years of studies, students of computing can choose to pursue two further years in one of these concentrations: computer science, software engineering or information technology. The software engineering concentration offers a course on software quality and another on software testing. The remaining state-sponsored university, National University (Universidad Nacional), does not include software quality or software testing as separate subjects within its degree or postgraduate programmes.

\subsubsection{Other Private Universities}

Software quality and software are not common in other computing degree programmes in Costa Rica. Universidad Invenio includes a course called Quality and Productivity in Enterprise Information and Telecommunication Technologies in its Enterprise ICT degree programme. Universidad Fidélitas launched a Postgraduate ('Licenciatura') Diploma on Software Quality Management that includes eight courses, a Research Seminar and a Graduation (thesis) Project; the courses include: quality management systems, knowledge management, software engineering, project formulation and evaluation, ICT quality models and standards, information system measurement, ICT quality auditing, management of ICT resources. The U. Fidélitas programme is not particularly geared towards software quality and less so towards software testing.

\subsection{Challenges and Prospects}

The author, being a university professor, inevitably biases his views from an educational and research perspective.

\subsubsection{Challenges}

In the author's view, these are some of the major challenges faced by the Hispanic America region with regards to software quality assurance and software testing:

- Faculty and university acknowledgement of software engineering as an important computing discipline, distinct from computer science and information systems [36] and recognising software quality, software testing and software maintenance as subjects that need study and space in curricula. Faculty members interested in software engineering are few compared to those specialised in more traditional areas of computer science or information systems. Those interested in software engineering do not lean particularly towards software quality or Software testing, usually preferring software technology, software design and software construction. 
- Educating future software professionals requires more than technical knowledge, it requires practice and experience. There are excellent resources available for teaching and organising courses related to programming, data structures, algorithms or databases - to name subjects which are quite mature and longstanding in computing curricula. In software testing, professors face the challenge of have concrete artefacts (code, models, plans, asset versions) for their students to test and analyse. Tool selection, for practical workshops is very challenging - as per its availability or suitability for teaching and learning-and also in terms of affordability by educational institutions. Software processes related to software testing, quality management, version control and configuration management need to be scaled down to educational settings, yet not be made too simple to become irrelevant or trivial. Measurement of quality and productivity needs product assets, project data and process history metrics. The challenge of curriculum-in-the-large can be faced successfully (as illustrated above), there is a major challenge of curriculum-in-the-small design and production (textbooks, laboratories, assets to be assessed or measured, presentations, software standards, workflow definitions, etc.).

- Industry recognition of software quality as subject of foremost importance. IT and software managers graduated when software quality and software testing were not part of their computing education (even less so if transferring from management or classic engineering degrees into computing). They do not know how to manage testing or quality assurance, they do not usually include the subjects in budgets, nor assign time and resources to activities related to them. Software testing and software quality assurance are absent, generally.

- Organisations more mature and knowledgeable about the costs of poor software quality will press suppliers, outsourcing companies and universities. Governments, banks and large corporations immersed in digitisation of their processes and businesses need to ensure the reliability of all software-intensive systems that support them.

- As with the rest of the world, Hispanic America will need to develop capabilities to address the challenges raised by mobile computing, usability, accessibility, Internet of Things, cyberphysical systems, safety-critical systems, secure systems, data-intensive analytic systems, artificial-intelligence powered systems, robotic and mechatronic systems, and much more.

\subsubsection{Prospects}

- Software engineering degree programmes will become more frequent in Hispanic America in the coming decade, as more people — from industry and academiarecognise that need for having an educated workforce developing and maintaining good-quality software systems. In 2011, the IEEE organised a workshop in Peru on computing curricula and nomenclature, with representatives from eight Latin American countries and also from Spain, USA and UK; they discussed nomenclature and approaches [37], and described common competencies for 
graduates from computing sub-disciplines, plus specific outcomes of education for graduates of computer science, information systems, software engineering, computer engineering and information technology programmes.

- On the supply side: Universities and training organisations interested in developing education or training programmes on software quality or software testing can look at, select, adapt or adopt: bodies of knowledge, software engineering standards, certification schemes, curricula guidelines and recommendations, (academic) accreditation standards and regulations. This may impact degree programmes, postgraduate diplomas, master's and specialty programmes, continuing education and training.

- Industry and academia can collaborate more. For example:

- Developing a common understanding of competencies, using frameworks such as SWECOM [22] or SFIA [38]

- Sharing information on technical skills and knowledge needed for good performance on specific jobs

- Validating what workplace-relevant, non-technical skills are more important for employers

- Developing internships, dual education, co-op terms, study visits

- Working together to support economic and community development in their areas

- Showing organizations' outreach and social responsibility

- Guest lecturing or workshop tutorials on practices, tools, standards and processes

- Providing artefacts for reviews (inspections), testing and analysis

- Opening suitably anonymised data on defects and productivity

- Faculty performing research with professionals at companies

- Companies' personnel undertaking postgraduate studies and developing theses on subjects relevant to their employers

- Co-leading comparative studies on tools, methods, standards, etc.

- Validating curricula development, updates or upgrades

- Reviewing course development, alignment, update or upgrade - at the curriculum level or in continuing education contexts

- Joint definition of integrative courses or projects for solving authentic problems in team-based efforts

- Interacting with advisory boards related to academic programmes or schools

- Sponsoring innovative graduation projects and providing incubation opportunities or mentoring

- Jointly sponsoring groups or communities interested in software quality and software testing

- The academic communities in Latin America interested in software engineering are growing, and will probably develop more specialist tracks or symposia in regional conferences.

- More scientific, engineering and industrial research will be needed in the field of software engineering, particularly related to software quality, software 
testing, software analysis, software integration, software aging and software maintenance.

As the 'digital transformation' of organisations progresses, more challengesand opportunities - lie ahead for those in Hispanic America interested in software quality and software testing.

Acknowledgements I thank Stephan Goericke and Agustina Gay of iSQI for the invitation to contribute, Santiago Castaño of the HASTQB for sharing statistical data, Carolina Triana for documents on Choucair Testing, colleagues of the JIISIC and SLISW Latin American conferences on software engineering and my family — for their patience (one more time!).

\section{References}

1. Barlas, S.: How critical is the shortage of IT workers? IEEE Computer. 30(5), 14-16 (1997)

2. Hoch, D., Purkert, G.: Secrets of Software Success. McKinsey \& Company (2000)

3. National Research Council: Building a Workforce for the Information Economy. National Academy Press (2001)

4. Computer World, USA/North American editions. Years 1997-2000

5. Mata, F., Jofré, A.: Estudio de oferta y demanda del recurso humano en la industria de software [Study of supply and demand of human resources by the software industry]. Pro-Software (Inter-American Development Bank, Caprosoft, Procomer, FunCenat) (2001)

6. Brenes, L., Govaere, V.: La industria del software en Costa Rica [The software industry in Costa Rica]. Comercio Exterior. 58(5), 303-311 (2008)

7. ACM/IEEE-CS Joint Task Force on Computing Curricula. The overview report: covering undergraduate degree programs in Computer Engineering, Computer Science, Information Systems, Information Technology, and Software Engineering. ACM Press and IEEE Computer Society Press (2005)

8. Sabin, M., Viola, B., Impagliazzo, J., Angles, R., Curiel, M., Leger, P., Murillo, J., Nina, H., Pow-Sang, J. A., Trejos, I.: Latin American perspectives to internationalize undergraduate information technology education. In Proceedings of the 2016 ACM Conference on Innovation and Technology in Computer Science Education (ITiCSE 2016). ITiCSE '16 Working Group Reports, July 09-13, 2016, Arequipa, Peru. A., Clear, E., Cuadros-Vargas, J., Carter, Y. Tupac (Eds.). Association for Computing Machinery (2016)

9. Marques, I.d.C.: History of computing in Latin America. IEEE Ann. Hist. Comput. 37(4), 10 $12(2015)$

10. GSMA The Mobile Economy Latin America and the Caribbean (2018)

11. World Economic Forum: The Future of Jobs. Employment, Skills and Workforce Strategy for the Fourth Industrial Revolution. World Economic Forum, Geneva, Switzerland (2016)

12. Experis: Tomorrow's Talent: Plugging the IT Skills Gap. Experis, London, UK (2013)

13. Capgemini Consulting: The Digital Talent Gap - Developing Skills for Today's Digital Organizations. London, UK, Capgemini Consulting (2013)

14. The Bureau of National Affairs: Building Tomorrow's Talent: Collaboration Can Close Emerging Skills Gap. Bloomberg BNA, Arlington, Virginia (2018)

15. Trejos, I., Cordero, A.: Learn-by-doing-collaboratively across the curriculum: Integrative projects at UCenfotec. In: IEEE World Engineering Education Conference - EDUNINE 2017. IEEE, Santos, BRAZIL (2017)

16. Naur, P., Randell, B. (eds.): Software Engineering. Report on a Conference sponsored by the NATO Science Committee. Garmisch, Germany, 7th to 11th (1968, October) 
17. Finkelstein, A., Kramer, J.: Software Engineering: A Roadmap. In: Proceedings of the Conference on The Future of Software Engineering. ACM (2000)

18. Bourque, P., Fairley, R. (eds.): Guide to the Software Engineering Body of Knowledge Version 3.0 (SWEBOK). IEEE Computer Soc, Los Alamitos, Calif. (2014)

19. Gotterbarn, D., Miller, K., Rogerson, S.: Software Engineering Code of Ethics and Professional Practice v5.2. ACM \& IEEE, New York, NY (1997)

20. ACM \& IEEE Computer Society: Software Engineering 2014 - Curriculum Guidelines for Undergraduate Degree Programs in Software Engineering. ACM \& IEEE Computer Society (2014)

21. Integrated Software \& Systems Engineering Curriculum (iSSEc) Project. Graduate Software Engineering 2009 (GSwE 2009) - curriculum guidelines for graduate degree programs in software engineering. Stevens Institute of Technology (2009)

22. IEEE. Software Engineering Competency Model Version 1.0 (SWECOM). IEEE Computer Society (2014)

23. https://asq.org/cert/software-quality-engineer

24. https://www.istqb.org/certification-path-root.html

25. Smerdon E.: An Action Agenda for Engineering Curriculum Innovation. 11th IEEE-USA Biennial Careers Conference, San Jose, California (2000, November 2-3)

26. National Academy of Engineering: The Engineer of 2020: Visions of Engineering in the New Century. National Academies Press (2004)

27. National Association of Colleges and Employers. Job Outlook (2019)

28. IEA. Graduate attributes and professional competencies, Version 3. International Engineering Alliance (2013)

29. ISTQB. Certified tester foundation level syllabus, Version 2018. ISTQB (2018)

30. Humphrey, W.: Introduction to the Team Software Process. Addison-Wesley, Boston, MA (2000)

31. Kruchten, P.: The Rational Unified Process: An Introduction, 3rd edn. Addison-Wesley, Boston, MA (2003)

32. Cherniss, C., Goleman, D.: The Emotionally Intelligent Workplace. Jossey-Bass, San Francisco, CA (2001)

33. Covey, S.: The Seven Habits of Highly Effective People. Free press, New York (1989)

34. ACM\&IEEE/CS: Curriculum Guidelines for Undergraduate Degree Programs in Software Engineering. New York, NY, ACM \& IEEE/CS (2004)

35. $\mathrm{O}_{*} \mathrm{NET}$. $\mathrm{O}_{*} \mathrm{NET}$ Resource Center. See www.onetcenter.org/overview.html, www.onetonline.org/, www.mynextmove.org/

36. Parnas, D.: Software engineering programs are not computer science programs. IEEE Softw. 16(6), 19-30. IEEE (1999)

37. Ramos, T., Micheloud, O., Painter, R., Kam, M.: IEEE Common Nomenclature for Computing Related Programs in Latin America. IEEE (2013)

38. SFIA: Skills Framework for the Information Age, SFIA 7 - The Complete Reference. SFIA Foundation, London (2018)

\section{Further Reading}

1. IPMA. Individual competence baseline for project, programme \& portfolio management. Version 4.0. International project management association (2015)

2. PMI. Project manager competency development framework, 3rd Ed. Project Management Institute (2017) 
Open Access This chapter is licensed under the terms of the Creative Commons Attribution 4.0 International License (http://creativecommons.org/licenses/by/4.0/), which permits use, sharing, adaptation, distribution and reproduction in any medium or format, as long as you give appropriate credit to the original author(s) and the source, provide a link to the Creative Commons licence and indicate if changes were made.

The images or other third party material in this chapter are included in the chapter's Creative Commons licence, unless indicated otherwise in a credit line to the material. If material is not included in the chapter's Creative Commons licence and your intended use is not permitted by statutory regulation or exceeds the permitted use, you will need to obtain permission directly from the copyright holder. 